Dr A. M. Posner (University of Western Australia) discussed a study of the surface reactivity and crystal morphology of goethite. A number of preparations of synthetic goethite, varying in the relative proportions of twinned and acicular crystals and BET nitrogen areas, were examined by electron microscopy, potentiometric titration, and adsorption of orthophosphate from solution. The zero point of charge and reactivity towards phosphate are not related to crystal morphology. The heterogeneity and anionic complexes on haematite surfaces were considered in a paper by Dr A. P. Prosser (Imperial College). There are considerable differences in the rate of dissolution of haematite by various concentrated acids which are attributed to surface anion complexes on the basal (001) surface only, and there is evidence of appreciable heterogeneity of this surface. Dodecylamine acts as a flotation collector for haematite at $p \mathrm{H} 1 \cdot 5$. It was necessary to activate the flotation by $\mathrm{Fe}^{+++}$and $\mathrm{Cl}^{-}$or $\mathrm{F}^{-}$or $\mathrm{SO}_{4}^{---}$; other combinations of cations and anions were tested and found ineffective. These phenomena are related to the attachment of two ligands to each exposed Fe atom on the active surface.

\section{Initiation of Lactation}

DR J. V. WHEELOCK writes:

Folley ${ }^{1}$ states that lactation in the ordinarily understood sense of a copious flow of normal milk is not initiated until parturition or shortly after. This view is also taken by your medical biochemistry correspondent $^{2}$ who considers that the synthetic activities of the mammary gland are "switched on" at birth. These statements imply that parturition, as such, is the stimulus for the initiation of lactation or, alternatively, that the stimulus is timed to as to coincide with parturition. There is evidence so suggest, however, that milk secretion can occur before parturition and that the initiation of lactation normally observed at parturition is directly caused by the commencement of milk removal, which invariably takes place at that time.

The fact that milk is present in the mammary gland at parturition shows that some secretion must have occurred before parturition. Confirmation is provided by the work of Wheelock and Rook ${ }^{3}$, who observed that lactose was present in the urine of pregnant cows for several days before parturition. The concentration of lactose increased to a maximum at parturition and then decreased rapidly. It was concluded that the lactose was being resorbed from the mammary gland because of the accumulation of milk within the gland.

Milk secretion before parturition has been demonstrated unequivocally by Rowland, Roy, Sears and Thompson". They milked cows twice daily for 14 days before the expected date of parturition. When milking first commenced, the amount of secretion obtained at each milking was usually very small. For most of the animals, a day on which the milk yield began to increase and then continued to do so until after parturition could clearly be distinguished. They found that the time of the initial increase in milk yield varied from 0-16 days before parturition. Rather similar results were obtained by Wheelock, Rook and Dodd ${ }^{5}$ when milking four cows throughout the whole of pregnancy. Milk yield decreased to a distinct minimum some days before parturition. In the four cows yield was at a minimum 20, 10 and 9 days and 1 day, respectively, before parturition. It seems probable that the beginning of the increase in milk yield observed by both groups of workers is in response to a hormonal stimulus.

Wheelock, Rook and Dodd ${ }^{6}$ established that suspension of milking in cows in mid-lactation caused a marked reduction in milk secretion. It was further shown that when milking at the usual twice daily intervals was resumed the rate of secretion recovered progressively. The results demonstrate that milk secretion is inhibited by accumulation of milk within the mammary gland.

Since the stimulus for the initiation of lactation almost certainly occurs before parturition, milk secretion before parturition would be inhibited by the accumulation of milk within the mammary gland. Consequently, the initiation of lactation at parturition would occur in response to the removal of milk. Recognition of this concept could facilitate investigations on the mechanism of the initiation of lactation.

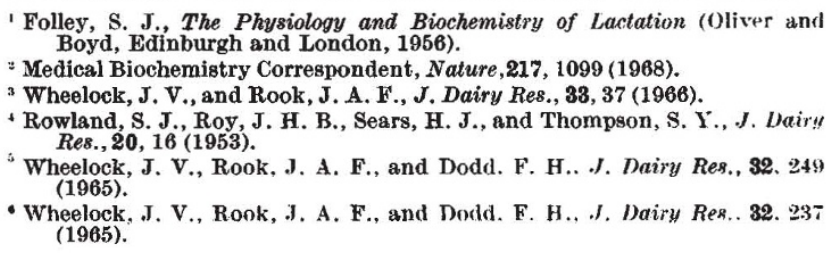

\section{Protein Evolution}

Professor EmIr Smith of the University of California, Los Angeles, delivered the twentieth annual Ciba Foundation lecture at the Ciba Foundation on May 1. Professor Smith described the work of his own group and others on the evolutionary changes of protein sequences. The most complete data are on cytochrome $c$ sequences which are now known for a large number of species of great evolutionary diversity, ranging from wheat germ to man. Cytochrome $c$ is an especially good choice for such a study since it is, speaking in evolutionary terms, one of the "oldest" of proteins. (Haemoglobin, for example, is by comparison a "new" protein.) As more and more sequences have been brought to light, the number of residues which are invariant and therefore functionally and structurally vital, so that their replacement would constitute a lethal mutation, has diminished to less than one-third of the total. Nearly all substitutions represent single base changes in the code. Professor Smith ranged eruditely and entertainingly over the subject of biochemical evolution and exposed for his large audience an entire area of molecular biology which has emerged only in the past few years.

Perhaps the most remarkable result-as yet unpublished-concerns the work in progress in his laboratory on the amino-acid sequences of histones. Histone fraction IV has been selected and studies are being carried out on this protein from two species at opposite ends of the evolutionary scale-calf thymus and pea seedlings. While work on cytochrome $c$ and other enzymes would lead one to expect a large number of differences in up to perhaps 75 per cent of the residues, there seem to be only two substitutions in histone fraction IV.

The sequences of the first nineteen residues of the chain have been fully determined and they are completely identical. The inference is that virtually all mutations are lethal and that therefore the structure 